\title{
Envenomation and consumption of poisonous seafood
}

\section{A Goonetilleke, J B Harris}

\section{Effects of naturally occurring toxins on the human nervous system and available treatments are discussed}

E xposure to natural toxins is becoming more commonplace because of greater worldwide travel, increasing captivity of exotic animals in private and institutional collections, and an expansion in the trade in tropical seafood. Although the effects of natural toxins are often trivial, some may result in neurological emergencies. A good understanding of the origin and management of neurotoxic poisoning is therefore important for the neurologist interested in tropical medicine. The true incidence of neurotoxic poisonings is impossible to ascertain because of underreporting. It has been suggested that each year there may be up to 1000 deaths in the Maharashtra state of India ${ }^{1}$ and 600 deaths in Sri Lanka resulting from snake bites, and 1000 to 2000 deaths in Mexico after scorpion stings. Tick paralysis has been estimated to cause the death of 10000 calves each year. ${ }^{2}$ There are thought to be around 50000 human victims of ciguatera poisoning each year. ${ }^{3}$

This editorial briefly outlines some of the effects of naturally occurring toxins on the human nervous system. We suggest that a general awareness of the circumstances in which exposure to natural toxins may occur and of the expression of poisoning in the form of clinical features will improve the prevention, detection, and management of these potentially fatal conditions. Three recent texts discussing some of these issues are available to the interested reader. $^{4-6}$

\section{ENVENOMATION \\ Snakes}

Venoms enable snakes to immobilise and initiate the digestion of their prey. The venom is usually introduced into the victim through a pair of fangs. Inspection of the bite site may show one or two fang puncture marks, single or multiple scratch marks where fangs were dragged across the skin, or a mixture of puncture marks and scratches. The presence of multiple puncture marks at different sites and in different orientations is suggestive of multiple bites and a potentially serious envenomation. Some snakes (for example, African and Asian spitting cobras) can emit a fine spray of venom from the tips of their fangs and thereby "spit" the venom for a distance of several metres into the eyes of their prey. The vipers and pit vipers (families Viperidae and Crotalidae) are relatively bulky snakes with large heads and fangs that fold into the roof of the mouth at restenvenomation always causes defibrination, extensive soft tissue haemorrhages, and bleeding from gums, old wounds and orifices. In contrast the snakes of the family Elapidae (for example, kraits, mambas, cobras) and of the related family Hydrophiidae (sea snakes) have short fixed fangs and inoculate a venom that is characteristically neurotoxic; an envenomation by these snakes, though often associated with defibrination, is rarely associated with significant haemorrhage or local tissue damage. This distinction may be misleading, as envenoming bites by some viperids and crotalids (for example, the Berg adder, Bitis atropos of Southern Africa, and the South American rattlesnake, Crotalus durissus terrificus) inflict an envenoming bite that produces significant neurotoxic signs; an envenoming bite by the Asian monocellated cobra, Naja kaouthia, is responsible for very severe and disfiguring local superficial necrosis.

The neurotoxic signs (for example, ptosis, ophthalmoplegia, dysphoria, inability to protrude the tongue or smile, generalised weakness) can be caused by the actions of three major groups of toxin. Postsynaptically active neurotoxins bind to the $\alpha$-subunit of the acetylcholine receptor (AChR) at the neuromuscular junction, causing what is somewhat loosely called a curare-like neuromuscular paralysis. These toxins are found in the venoms of all elapid and hydrophid snakes. Presynaptically active neurotoxins are found in the venoms of many elapid snakes, especially the elapid snakes of Australia and Papua New Guinea, the kraits of South East Asia, and in the venoms of some vipers and crotalids (for example, Berg adder, South American rattlesnake, Russell's viper of southern India and Sri Lanka). The toxins are active phospholipases. They bind to motor nerve terminals, causing the depletion of synaptic vesicles and the destruction of the nerve terminal and the terminal parts of the motor axon. Many of the presynaptically active neurotoxic phospholipases are also potent myotoxins, and therefore the victims of envenoming bites by some snakes (for example, sea snakes, Australian elapids, Berg adders, South American rattlesnakes) may be weak as a result of both neurotoxic and myotoxic damage.

The varied aetiology of neurotoxic involvement in snake envenomation influences the treatment and management of individual snakebites. Elapid snakes will always inoculate postsynaptically active neurotoxins. Severely envenomed victims will need ventilatory support. The dissociation of neurotoxins from AChR is probably accelerated by antivenom ${ }^{7}$ and possibly by anticholinesterases. If ventilatory support is maintained and appropriate treatment with antivenom and possibly anticholinesterases is available, recovery will be rapid and uneventful. If appropriate antivenoms are unavailable respiratory support for 24 hours will usually allow full recovery. Venoms of most elapid snakes (for example, cobras and coral snakes) typically contain only postsynaptically active neurotoxins. If the victim exhibits neurotoxic signs but shows little or no response to the relevant antivenoms or anticholinesterases it is likely that the venom contains presynaptically active neurotoxins; the victim will therefore need ventilatory support and conservative management for several days until damage to the neuromuscular systems are repaired. Myotoxicity may be recognised by the presence of muscle pains, especially on movement, and myoglobinuria. ${ }^{8}$ Such patients need careful management to prevent acute renal failure caused by the release of myoglobin from the damaged muscle. Envenoming bites by the South American rattlesnake, Australian tiger snake, Australian king brown (mulga) snake, the taipans of Australia and Papua New Guinea and sea snakes are particularly liable to cause muscle damage.

Two groups of elapid snakes, the kraits and mambas, are worthy of special mention. Kraits are nocturnal, snake-eating animals. Envenoming bites may be so innocuous as to fail to arouse a sleeping victim, and it is uncommon for the offending snake to be seen. A victim who sleeps in the open or in a simple rural shelter anywhere in South East Asia and who awakes with morning weakness, loin pain, and a metallic taste in the mouth has possibly been bitten by a krait. The difficulty of identifying a biting snake, and the fact that the onset of serious weakness may be slow can mean that victims often delay seeking medical attention. This can be a significant problem. Envenoming bites by kraits are difficult to manage because the 


\section{Table 1 Envenomation}

\begin{tabular}{|c|c|c|c|}
\hline \multicolumn{2}{|l|}{ Envenoming species } & Location & Features \\
\hline \multicolumn{4}{|l|}{ Snakes } \\
\hline Elapidae & $\begin{array}{l}\text { Cobras, kraits, mambas, coral } \\
\text { snakes, Australasian venomous } \\
\text { snakes }\end{array}$ & Africa, Asia, Australasia & $\begin{array}{l}\text { Local effects unusual. * Early neurotoxic effects, especially } \\
\text { blurred vision and ptosis. Some Australasian elapids } \dagger \text { cause } \\
\text { haemostatic effects, rhabdomyolysis and renal failure }\end{array}$ \\
\hline Viperidae/Crotalidae & $\begin{array}{l}\text { Vipers, adders, rattlesnakes, } \\
\text { moccasins }\end{array}$ & $\begin{array}{l}\text { Africa, Asia, Europe, } \mathrm{N} \text { and } \mathrm{S} \\
\text { America }\end{array}$ & $\begin{array}{l}\text { Severe local and haemostatic effects (especially gingival } \\
\text { bleeding) common. Hypertension and shock (especially } N \\
\text { American rattlesnakes). Renal failure commonest cause of } \\
\text { death. Neurotoxic effects unusualf }\end{array}$ \\
\hline Colubridae & $\begin{array}{l}\text { Comprise } 2 / 3 \text { all known species of } \\
\text { snake }\end{array}$ & $\begin{array}{l}\text { Africa, Asia, Australasia, Europe, } \\
\text { S America }\end{array}$ & $\begin{array}{l}\text { Envenomation may develop slowly over many days, varying } \\
\text { from local swelling to repeated vomiting, abdominal pain, } \\
\text { headache, haemostatic effects and renal failure }\end{array}$ \\
\hline Atractaspididae & Burrowing asps or stiletto snakes & Africa, Middle East & $\begin{array}{l}\text { Local effects. Violent gastrointestinal (nausea, vomiting, } \\
\text { diarrhoea) and respiratory (dyspnoea, respiratory failure) } \\
\text { effects }\end{array}$ \\
\hline Hydrophiidae & Sea snakes & Pacific and Indian oceans & $\begin{array}{l}\text { Initial headaches, thick feeling of tongue. Flaccid paralysis } \\
\text { and rhabdomyolysis later }\end{array}$ \\
\hline \multicolumn{4}{|l|}{ Spiders } \\
\hline Latrodectus & Black widow or redback spiders & $\begin{array}{l}\text { Asia, Australasia, Europe, N } \\
\text { America }\end{array}$ & $\begin{array}{l}\text { Painful needle-like bite, may lead to painful local } \\
\text { lymphadenopathy within } 30 \text { minutes. Painful muscle } \\
\text { spasms§ and rigidity throughout body. Autonomic effects }\end{array}$ \\
\hline Phoneutria & Wandering or banana spiders & S America & $\begin{array}{l}\text { Painful bite leading to burning sensation, spreading } \\
\text { proximally in limb. Autonomic effects, temporary blindness, } \\
\text { respiratory distress }\end{array}$ \\
\hline Atrax & Funnel web spiders & Australasia & $\begin{array}{l}\text { Painful bite. Neurotoxic symptoms (perioral numbness, } \\
\text { spasms of tongue) may occur within } 10 \text { minutes. Autonomic } \\
\text { effects, muscle spasms, dyspnoea, and coma }\end{array}$ \\
\hline \multicolumn{4}{|l|}{ Scorpions } \\
\hline Buthus & & N Africa, S Europe, Middle East & $\begin{array}{l}\text { Painful sting. Cardiac dysrythmias, thirst, urinary retention, } \\
\text { mydriasis, aphonia }\end{array}$ \\
\hline Leiurus & & N Africa, Middle East & Painful sting. Cardiac and respiratory failure. Muscle \\
\hline Centruroides & & N America, Mexico & $\begin{array}{l}\text { spasms and twitching. Autonomic effects, irritability. } \\
\text { Coagulation defects in some species of Centruroides }\end{array}$ \\
\hline Androctonus & & N Africa, ${ }^{* *}$ Middle East & $\begin{array}{l}\text { Painful sting. Hypertension, cold peripheries, } \uparrow \text { lacrimation } \\
\text { and salivation, dyspnoea }\end{array}$ \\
\hline Tityus & & Caribbean, S America & $\begin{array}{l}\text { Painful sting, spreads to affect entire limb. Numbness, } \\
\text { tightness in throat, muscle twitching, respiratory paralysis. } \\
\text { Trinidad black scorpions lead to severe gastrointestinal } \\
\text { effects } † \text { and cardiac irregularities }\end{array}$ \\
\hline Heterometrus & & Asia & $\begin{array}{l}\text { Painful sting, effects vary from mild (nose itching, salivation, } \\
\text { dyspnoea) to severe (local swelling, haemorrhage and } \\
\text { weakness in affected limb). Cardiovascular effects common }\end{array}$ \\
\hline Mesobuthus & & Asia (India) & $\begin{array}{l}\text { Severe cardiovascular effects common. Fatalities reported in } \\
\text { adults as well as children }\end{array}$ \\
\hline \multicolumn{4}{|l|}{ Ticks } \\
\hline Acari & & Australasia, N America & $\begin{array}{l}\text { Progressive weakness and paraesthesiae. Respiratory failure } \\
\text { commonest cause of death. Children aged } 1-5 \text { years mostly } \\
\text { affected. Tick usually found in scalp, especially behind ears }\end{array}$ \\
\hline \multicolumn{4}{|c|}{$\begin{array}{l}\text { Local effects=skin blistering and necrosis, pain, tenderness and swelling of local lymph nodes, swelling of limb. Neurotoxic effects=early ptosis, aphonia, } \\
\text { external ophthalmoplegia, weakness, respiratory failure, autonomic effects (blurred vision, hypersalivation, piloerection). Haemostatic } \\
\text { effects=defibrination, haemolysis, haemorrhages. "Local pain, swelling, blistering, necrosis, and painful regional lymphadenopathy can occur with Asian } \\
\text { and African spitting cobras. Corneal erosions may occur if venom spat into eyes. †Examples include tiger snake, taipan and common brown snake. } \\
\ddagger \text { †eurotoxicity a significant feature of envenomation in a few species (for example, C } d \text { terrificus, Far Eastern Agkistrodon sp, Bitis atropos, Sri Lankan } D \\
\text { russelii pulchella). §Effects include a painful grimace ("facies latrodectisimina"). TVenom of } C \text { sculpturatus may cause platelet aggregation in children. } \\
\text { **Androctonus accounts for } 80 \% \text { of all scorpion stings in N Africa. ††Nausea, vomiting, severe abdominal pain, haematemesis, hyperglycaemia, acute } \\
\text { pancreatitis. }\end{array}$} \\
\hline
\end{tabular}

venoms are rich in pre-synaptically active $\beta$-bungarotoxins, and so recovery may be prolonged. ${ }^{9}$ Bites by mambas (an exclusively African genus) are always serious. Their venoms contain postsynaptically active neurotoxins that are typical of elapids, and a number of unique toxins some of which target muscarinic ACh receptors. It is not known to what extent these toxins complicate an overwhelming syndrome of post-synaptic neurotoxicity, but a single paper described decreased parasympathetic activity in an envenoming incident by the Malaysian krait (mydriasis, tachycardia, constipation, and defective micturition) lasting for up to two years (table 1$).{ }^{10}$
The defibrination of the blood may give rise to bleeding into the CNS. This is a rare but difficult neurological problem associated with some snakebites. ${ }^{11}{ }^{12}$ It is often slow in onset and may not be clinically apparent for several weeks. ${ }^{13}$

\section{Treatment of snakebites}

1 Appropriate first aid at the scene of the envenomation can be critical and includes patient reassurance, immobilisation of the bitten limb, and application of a pressure bandage (as if for a sprain) over the bite site. These manoeuvres may delay toxin absorption. Care should be exercised when releasing pressure bandages in case there is a sudden release of venom into the systemic circulation.
Other interventions (for example, cutting, sucking, freezing, cauterising, application of arterial tourniquets, foreign materials, or chemicals at bite site, etc) are potentially dangerous and should be avoided. The pain after snakebites may be severe, but can usually be controlled by standard analgesics-narcotic analgesics should be avoided because of the risks of respiratory depression.

2 A description of the offending snake should be obtained if possible-if it has been killed it should be kept for formal identification.

3 If there are signs of systemic poisoning (ptosis and dysphonia are early indicators of neurotoxicity) the patient should 

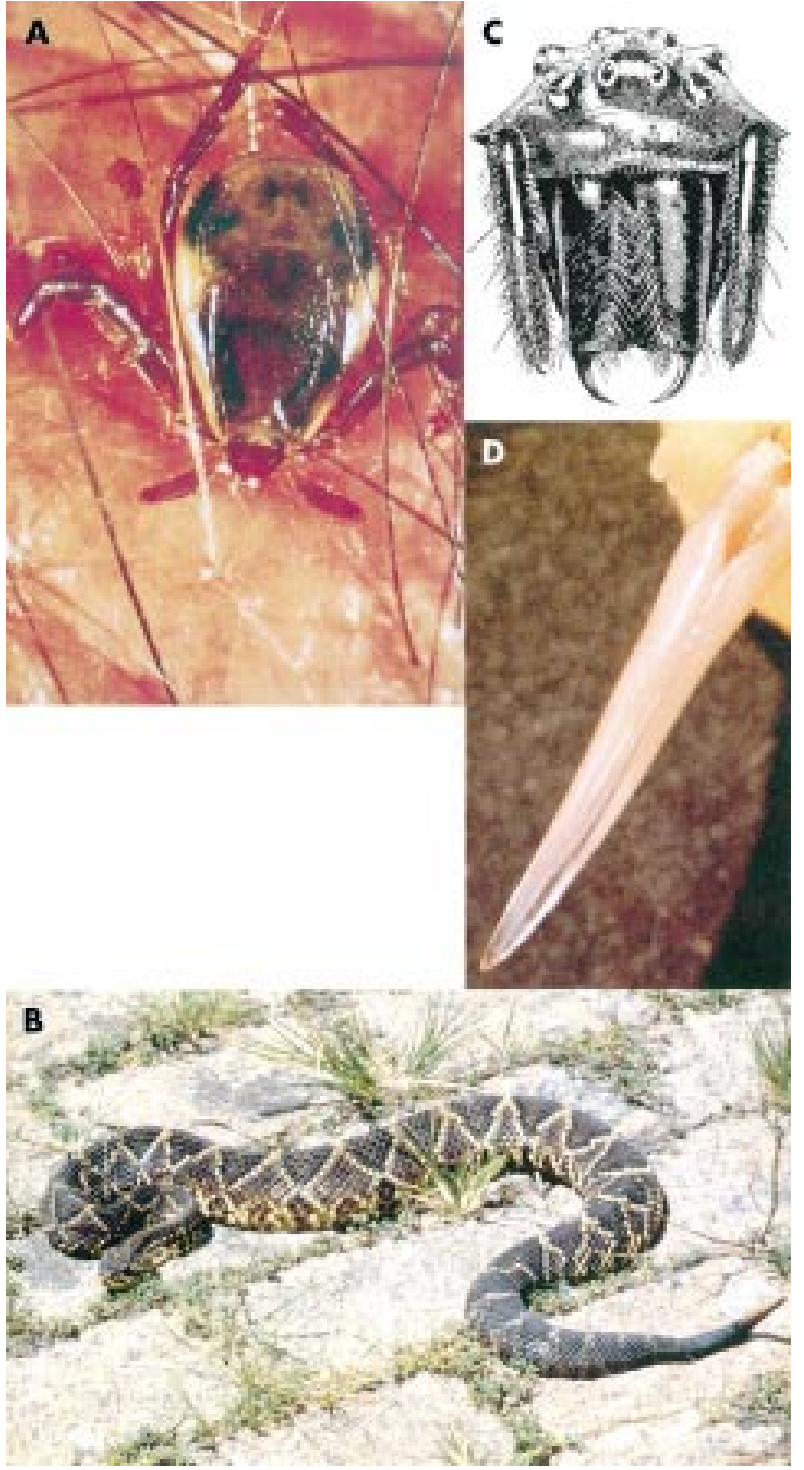

Figure 1 (A) Australian paralysis tick (Ixodes holocyclus). (B) South American rattlesnake (Crotalus durrissus terrificus). (C) Head of Latrodectus (black widow spider) to show fangs. (D) Fang of venomous snake.

be transferred to the local hospital or clinic. Swabs of the bitten area and blood samples should be taken for detection of venom antigens and coagulation profile. The blood pressure, respiratory and renal function should be closely monitored, and patients should be observed for signs of neurotoxicity, myoglobinuria, cardiac abnormalities, and coagulation disturbances.

4 Specific antivenoms (ideally active against the venoms of local snakes) should be administered, with facilities available to deal with any early or delayed immunological reactions against the antivenoms. The same dose is given to children as for adults. Multiple doses of antivenom may be required to control circulating levels of toxins, and should be given until the patient shows no signs of relapsing.

5 Anticholinesterases may have potential value in treating neurotoxic signs.
Envenomation involving presynaptically active neurotoxins or myotoxic toxins are more difficult to manage and patients may require supportive treatment (for example, artificial ventilation), sometimes for weeks, until the nerve terminals and/or muscle fibres have regenerated.

\section{Spiders and scorpions}

The venoms of spiders and scorpions are primarily used for the capture of invertebrates. The composition of the venoms reflects this function, with hydrolytic enzymes such as hyaluronidase and phospholipases being typical components as well as small chemical mediators such as serotonin and a range of toxins targeting $\mathrm{Na}^{+}, \mathrm{K}^{+}$, and $\mathrm{Ca}^{2+}$ channels specific to invertebrate nervous systems. The spiders and scorpions that are dangerous to humans all inoculate toxins with a high level of affinity for $\mathrm{Na}^{+}$,
$\mathrm{K}^{+}$, and $\mathrm{Ca}^{2+}$ channels in mammals. Although the toxins of spider and scorpion venoms have been widely studied because of their importance as tools in neuroscience research, it is still difficult to relate knowledge of molecular and cellular biology of individual toxins to the clinical expression of envenoming spider bites and scorpion stings in human victims (table 1 ).

\section{Spider bites}

Bites by Latrodectus species (the black widow, red-back or button spiders), Atrax species (the funnel web spiders), Missulena species (the mouse spiders), and Phoneutria (the banana spiders) are clinically important. Latrodectus is the only widespread genus and is found all over the warmer parts of the world, avoiding only the cooler temperate and cold regions. Atrax and Missulena are Australasian spiders and Phoneutria is Brazilian. Bites by exotic spiders are not unknown as the result of the transport of spiders in shipments of goods. ${ }^{14}$

Latrodectus is small and may not be immediately identified as the biting animal. Bites are painful and the symptoms and signs of envenomation (for example, hyperexcitability, local sweating, colic or abdominal stiffness, fasciculation, muscular weakness, tachycardia, and palpitations) develop slowly. The venom is complex but the toxins responsible for the neurotoxic signs are the latrotoxins. The toxins cause the release of transmitters (by mechanisms that are as yet unclear) from nerve terminals in both the autonomic and somatic nervous system and that is reflected in the symptoms and signs of such bites. Acute renal failure and a late Horner's syndrome have both been reported as complications arising from latrodectism, ${ }^{15} 16$ but such complications seem rare.

Funnel web spiders are large and can cause a lethal bite. The bite is painful, partly because the fangs are large and partly because the venom is acidic. The venoms are complex, but the group of toxins responsible for most problems in humans are the atracotoxins. These toxins delay the inactivation of $\mathrm{Na}^{+}$channels in the nervous system, causing spontaneous repetitive firing in peripheral nerves. The signs of envenomation (for example, hyperexcitability, fasciculation, fluctuating blood pressure, muscular weakness) ${ }^{17}$ all reflect the excessive discharge of transmitter from nerve terminals in the autonomic and somatic nervous system. Missulena venoms contain toxins structurally and functionally similar to the atracotoxins, and the symptomology after a bite is also similar to that of funnel-web spiders.

The venom of Phoneutria has not been fully characterised but toxins that block $\mathrm{Ca}^{2+}$ channels, activate $\mathrm{Na}^{+}$channels and inhibit $\mathrm{Na}^{+}$channel inactivation have all 
been identified. Envenomation by Phoneutria gives rise to all of the signs of autonomic hyperactivity and is entirely consistent with a venom induced enhanced release of neurotransmitters from nerve terminals in all parts of the autonomic nervous system.

\section{Treatment of spider bites}

l Immediate first aid should include reassurance, maintenance of the airway and respiration. If there is ready access to a clinic holding stocks of antivenom immobilisation and splinting of the bitten limb before moving the patient is recommended in the treatment of bites by Atrax, but not for bites by Latrodectus. This is because signs of systemic envenoming with Latrodectus develop slowly and antivenom can be used as soon as systemic signs began to appear.

2 Calcium gluconate is useful in relieving the pain and muscle spasms caused by Latrodectus. Atropine and diazepam are effective for bites by Atrox. Although corticosteroids may relieve some symptoms they have no effect on overall mortality.

3 Specific antivenoms for Latrodectus, Phoneutria and Atrax are available for the seriously envenomed patient. They should be given in facilities available to deal with any immune reactions against the antivenoms.

\section{Scorpions}

Scorpions also use venoms to subdue prey items, most of which are invertebrates. Their venoms contain toxins specific for invertebrate ion channels as well as small mediators such as serotonin and enzymes such as phospholipases and hyaluronidase. The effects of a sting on human victims are largely attributable to the presence of serotonin and other mediators and of toxins that act on vertebrate ion channels to either block $\mathrm{K}^{+}$channels or delay the inactivation of $\mathrm{Na}^{+}$channels. These toxins enhance the release of transmitters from nerve terminals in all parts of the autonomic and somatic nervous systems.

Scorpion stings are a significant problem throughout the tropical and subtropical world, and the specific symptoms of an envenoming sting can vary greatly according to the geographical region, the species involved, and the age of the victim. All stings are painful and all produce symptoms that have the characteristics expected of toxins that cause the enhanced release of neurotransmitters (for example, vomiting, colic, diarrhoea, sweating, pilo-erection, hypertension, cardiac arrythmia, priapism, etc). Secondary damage, especially to the cardiac and pulmonary systems, results from both the "autonomic storm" and the peripheral mediators either inoculated with the venom or released as a result of mast cell degranulation. ${ }^{18}$ This is an important consideration for treatment as even successful antivenom therapy (in terms of venom clearance) may not reverse secondary damage and its consequences.

\section{Treatment of scorpion stings}

1 Pain at the sting site may be relieved by local infiltration of local anaesthetics or a ring block. Narcotic analgesics should be avoided in patients showing features of neurotoxicity as they may contribute to respiratory failure.

2 Available specific antivenoms should be given immediately to young children stung by dangerous species or to patients showing signs of systemic involvement. The efficacy of antivenom is unproven if administration is delayed for more than two hours. Only a few of the antivenoms available have been subject to formal clinical trials, and the efficacy of many antivenoms is questionable.

3 Cardiac arrhythmias, convulsions and pulmonary damage may require additional management because the problems are probably secondary and are not reversed during antivenom therapy.

Ticks

Human tick paralysis occurs most commonly in eastern Australia and North America. The tick may be picked up directly from the countryside or from domestic animals, particularly dogs. Neurotoxins (present in the tick's saliva) are introduced while the tick engorges itself with the host's blood, and cause a presynaptic neuromuscular block possibly by impairing the excitation-secretion coupling at the neuromuscular junction by reducing calcium availability. ${ }^{19}$ Children aged $1-5$ years are most commonly affected, with a non-specific prodome (for example, anorexia, lethargy, and irritability) followed by the onset of an unsteady gait and then an ascending, symmetrical, flaccid paralysis resembling the Guillan-Barre syndrome. ${ }^{20} \mathrm{~A}$ fatal paralysis may be caused by a single tick. Ticks embedded behind the ear or in the external auditory meatus can cause an ipsilateral facial weakness. The diagnosis depends on finding the tick, the scalp and the back of the ear being common sites where they are to be found.

\section{Treatment of human tick paralysis}

1 Treatment consists of carefully detaching the tick from the host while keeping it intact. Killing the tick with pyrethrin based insecticides before removal may help. Older techniques (for example, heat, lighted matches, alcohol, etc) should generally be avoided. Human tick paralysis encountered in North America are attributable to Dermacentor andersoni and $D$ variabilis, and there is usually a rapid clinical recovery after tick removal. ${ }^{21}$ In contrast, cases encountered in eastern Australia are caused by Ixodes holocyclus and maximal weakness may not be achieved for up to 48 hours after removal of the tick, with full recovery taking several weeks.

2 Supportive therapy (for example, assisted ventilation) may be required.

3 Specific antitoxin is not very effective, and can be associated with a high incidence of allergic responses and serum sickness. Its use is therefore only recommended for patients at high risk of a poor outcome, such as severely affected or very young patients.

\section{CONSUMPTION OF POISONOUS SEAFOOD}

In this brief review we concentrate on neurologically important poisonings resulting from the consumption of seafood. All the well documented syndromes that are characteristic of seafood poisoning result either from the accumulation of algal or bacterial toxins through the food chain, or from toxins produced by symbiotic micro-organisms. ${ }^{22}$ The diagnosis of seafood poisoning is primarily by exclusion as most incidents share common features of nausea, vomiting, diarrhoea and gastrointestinal pain and an onset time of 3-12 hours. Many documented cases of severe poisoning involve holiday makers enjoying an exotic meal before presenting to a physician on their return home. The principal syndromes of importance are ciguatera, shellfish poisoning (paralytic, neurotoxic, amnesic, and diarrhetic forms), tetrodotoxic and palytoxic fish poisoning.

\section{Ciguatera fish poisoning}

The syndrome of ciguatera poisoning has been discussed in detail in a recent review. ${ }^{3}$ Occasional references to ciguatera poisoning are to be found in the world literature dating back to the 16th century, with clearer references originating from the West Indies in the 18th century. The term ciguatera is derived from the American-Spanish word cigua, the name of a poisonous sea snail (Livona pica) that produces a similar illness in the Spanish Antilles. Ciguatera poisoning is caused by the consumption of coral grazing fishes or of the larger pelagic predatory fishes (for example, snappers, groupers, and sea trout). Most cases of poisoning are to be found in the Caribbean, Pacific Islands (including the north eastern seaboard of Australia), and the United States (especially Hawaii and south eastern Florida); however, the increasing worldwide trade in exotic fish has led to outbreaks throughout the world, including Europe. The global incidence of such poisoning has been estimated at between 50000 and 500000 cases per year (table 2).

The toxins responsible for the clinical features include ciguatoxins (which can 
Table 2 Seafood poisoning

\begin{tabular}{|c|c|c|c|}
\hline \multicolumn{2}{|c|}{ Cause of seafood poisoning } & \multirow{2}{*}{$\begin{array}{l}\text { Location } \\
\text { All tropical/subtropical regions, } \\
\text { especially Caribbean, Indo-Pacific }\end{array}$} & \multirow{2}{*}{$\begin{array}{l}\text { Features } \\
\text { Nausea and vomiting within 3-24 } \\
\text { hours of consumption of shellfish } \\
\text { Abdominal pain, numbness and } \\
\text { tingling of mouth and digits. Unstable } \\
\text { heart rate and blood pressure }\end{array}$} \\
\hline Ciguatera fish poisoning & $\begin{array}{l}\text { Consumption of large fish, such as moray eel, } \\
\text { groupers, snappers and reef grazers } \\
\text { (including Xanthic crabs) Principal toxins are } \\
\text { ciguatoxins }\end{array}$ & & \\
\hline $\begin{array}{l}\text { Paralytic shellfish } \\
\text { poisoning (PSP) }\end{array}$ & $\begin{array}{l}\text { Alexandrium, Gymnodinum, Gonyaulax } \\
\text { Principal toxin are saxitoxins }\end{array}$ & All areas, temperate and tropical & $\begin{array}{l}\text { Tingling and numbness of mouth and } \\
\text { digits, headache. Neuromuscular } \\
\text { weakness after } 3-24 \text { hours of } \\
\text { consumption of shellfish }\end{array}$ \\
\hline $\begin{array}{l}\text { Neurotoxic shellfish } \\
\text { poisoning (NSP) }\end{array}$ & Gymnodinium Principal toxin are brevetoxins & Gulf of Mexico, Florida & $\begin{array}{l}\text { Similar to PSP but milder. Often } \\
\text { associated with respiratory difficulties }\end{array}$ \\
\hline $\begin{array}{l}\text { Amnestic shellfish } \\
\text { poisoning (ASP) }\end{array}$ & Pseudonitzschia Principal toxin is domoic acid & $\begin{array}{l}\text { Temperate: N America, N Europe, S } \\
\text { Antipodes }\end{array}$ & $\begin{array}{l}\text { Nausea, vomiting, diarrhoea after } 3-6 \\
\text { hours. Dizziness in more severe cases } \\
\text { Most severe cases associated with } \\
\text { confusion, short-term memory loss and } \\
\text { seizures }\end{array}$ \\
\hline $\begin{array}{l}\text { Diarrhetic shellfish } \\
\text { poisoning (DSP) }\end{array}$ & $\begin{array}{l}\text { Dinophysis and Prorocentrum Principal toxin is } \\
\text { okadaic acid }\end{array}$ & All areas, temperate and tropical & $\begin{array}{l}\text { Diarrhoea, vomiting and stomach } \\
\text { pains develop after } 30 \text { minutes to } 24 \\
\text { hours of consumption of shellfish }\end{array}$ \\
\hline $\begin{array}{l}\text { Tetrodotoxin fish } \\
\text { poisoning }\end{array}$ & $\begin{array}{l}\text { Consumption of puffer fish liver, ovaries } \\
\text { Principal toxins are tetrodotoxins }\end{array}$ & Indo-Pacific, especially S E Asia & $\begin{array}{l}\text { Nausea, vomiting, numbness, tingling } \\
\text { and neuromuscular weakness }\end{array}$ \\
\hline Palytoxic fish poisoning & Palythoa Principal toxins are palytoxins & Indo-Pacific and Caribbean & $\begin{array}{l}\text { Indistinguishable from ciguatera fish } \\
\text { poisoning }\end{array}$ \\
\hline
\end{tabular}

exist in many forms), maitotoxin, and scaritoxin. The toxins are initially formed by the dinoflagellate Gambierdiscus toxicus, ${ }^{23}{ }^{24}$ which are then accumulated by grazing fish and subsequently concentrated along the food chain. The toxins are to be found in their highest concentration within the liver, viscera, and gonads of the larger fish. The toxins are lipid soluble, relatively heat stable, and resistant to gastric acid. Once the ciguatoxins are absorbed they bind to the voltage sensitive sodium channels of cellular membranes.

Features of acute ciguetera poisoning usually occur within one to six hours (range of few minutes up to 30 hours) of ingestion. ${ }^{25}$ The onset of the disorder may be with either gastrointestinal (for example, abdominal cramps, nausea, vomiting, watery diarrhoea) or neurological (for example, paraesthesiae, dysaesthesiae, blurred vision, transient blindness, vertigo, ataxia, tremor, insomnia) symptoms. Paraesthesiae are initially circumoral in nature and then spread centrifugally to the limbs, and usually persist for many days and on occasions for many weeks. The dysaesthesiae are characterised by a painful reversal of hot-cold sensation. The average duration of illness is 8.5 days, with a median hospital stay of six days. ${ }^{26}$ The chronic effects of ciguatera poisoning has been estimated to affect $3 \%-20 \%$ cases of acute poisoning, and is characterised by excessive fatigue. Other chronic effects described include hypersomnolence, peripheral neuropathy, and polymyositis.

General treatment consists of attempts at reducing further toxin absorption by inducing emesis or performing a gastric lavage followed by the administration of activated charcoal. Specific treatment consists of the administration of hyperosmotic mannitol infusions, ${ }^{27} 28$ with a report of positive responses being noted within 10 minutes in all of 24 patients treated and a mean time to complete resolution of symptoms of 10 hours and complete recovery in 17 patients within 48 hours. ${ }^{27}$ Because of the osmotic effects of mannitol treatment any dehydration present attributable to vomiting should first be corrected. The recommended regimen is the administration of $10 \mathrm{ml} / \mathrm{kg}$ of $20 \%$ mannitol, infused slowly over a minimum period of 30-45 minutes ${ }^{28}$; the dose may be repeated after three to four hours, and again the following day. The mechanism of action of mannitol in ciguatera poisoning may be by competitive inhibition of the toxin's effect on $\mathrm{Na}^{+}$channels, or by neutralisation of the toxin. The overall mortality of acute poisoning was estimated to be $0.1 \%$ in a series of 3009 poisonings during 1964-1977 (that is, an era prior to the routine use of mannitol) in the French Polynesia and New Caledonia Pacific Islands group. ${ }^{29}$

\section{Shellfish poisoning}

Cases of shellfish poisoning typically arise after the consumption of filter feeding shellfish (for example, mussels, scallops, clams), the causative agents being dinoflagellates that are ingested by the shellfish during feeding. The toxins responsible are non-proteins that are stable and resist most of the forms of rapid cooking typically applied to seafood.

Paralytic shellfish poisoning (PSP) is caused by the ingestion of toxin producing dinoflagellates of several genera by filter feeding shellfish. The toxins involved are all members of a family of gonyautoxins, the best known of which is saxitoxin. The gonyautoxins blocks voltage gated channels, thus blocking action potential generation in skeletal muscle and sensory and motor axons. The early signs of gastrointestinal disturbance (three to six hours) may progress to include numbness of mouth and digits, visual disturbance, dysphagia, neuromuscular weakness and, in severe cases, a potentially fatal respiratory paralysis. Treatment is symptomatic, but observation is essential because the development of severe paralysis may be relatively slow (up to 24 hours). Recovery takes three to seven days and is usually uneventful. ${ }^{30}$

Neurotoxic shellfish poisoning (NSP) is much rarer than PSP. It is largely confined to the Florida coast, the Gulf of Mexico, and possibly the east coast of South America. The responsible dinoflagellate is usually Gymnodinium brevis. This is accumulated by filter feeding shellfish, which in turn become a carrier for a group of toxins collectively known as the brevetoxins. These toxins are lipid soluble and they bind to a poorly defined region of the voltage gated $\mathrm{Na}^{+}$channel to cause repetitive firing of action potentials. The toxins may also enhance the release of transmitters from autonomic nerve terminals. It has also been suggested that they initiate the degranulation of mast cells and thus contribute to respiratory problems (see below). The symptoms of NSP depend on the route of ingestion. If infected shellfish are eaten the symptoms are similar to, but less severe than, those associated with PSP. The brevetoxins are powerful irritants and inhalation of aerosols containing the toxins (for example, sea spray, or sprays created during storms) causes bronchoconstriction and lacrimation rather than "neurological" signs. The possible role of 
histamine and other peripheral mediators from mast cells has been noted. No human fatalities have been reported and recovery is rapid and uneventful.

Amnesic shellfish poisoning is also caused by consumption of filter feeding shellfish that have accumulated domoic acid from the causative dinoflagellates of the genera Pseudonitzchia or Nitzchia. Domoic acid is an excitatory neurotoxin active at kainate receptors in the CNS. A major outbreak occurred in Nova Scotia in 1987 and 1998 and minor outbreaks have occurred in the Pacific coast of USA, Scandinavia, and New Zealand. The syndrome begins with gastrointestinal disease, but in severe poisoning patients become dizzy, ataxic, and experience cognitive difficulties. Treatment is symptomatic, but the loss of short-term memory, confusion, and seizures may be permanent. $^{31}$

Diarrhetic shellfish poisoning is widespread and causes gastrointestinal problems without neurological symptoms. The responsible toxin is okadaic acid. Recovery is uneventful after two to three days.

It is important to note that although shellfish poisoning (and ciguatera) are caused by the ingestion of blooming species of marine algae, a bloom is not a formal requirement. This is because the dinoflagellates involved can rest in the benthos on the sea bottom in an encysted form. Activation or disturbance of the benthos may disturb these forms and allow their ingestion in the absence of a bloom.

\section{Tetrodotoxin fish poisoning}

Tetrodotoxic poisoning usually results from the consumption of puffer fish, but bites by the blue ringed octopus (an Australasian species) can also result in the introduction of tetrodotoxin from the saliva. ${ }^{32}$ The toxin is probably produced by a marine Vibrio that enjoys a symbiotic relationship with the host. The toxin is concentrated in the skin and viscera of fish. Most cases of poisoning occur in Japan or in Japanese communities elsewhere where puffer fish are eaten as a delicacy. The principal toxin (tetrodotoxin) blocks the voltage gated $\mathrm{Na}^{+}$channel at the same site as saxitoxin and causes numbness, tingling, visual disturbances, and a potentially fatal neuromuscular weakness within 10-15 minutes of ingestion. Treatment is symptomatic and recovery is usually uneventful provided the patient in neuromuscular paralysis is artificially ventilated and the circulation is maintained.

\section{Palytoxic fish poisoning}

Palytoxic poisoning is encountered in the Indo-Pacific and Caribbean, and results from the consumption of fish, soft crabs or other animals that graze on the tropical soft anthozoan Palythoa, or of the larger predatory fish that feed on the primary grazers. The toxins responsible are known as palytoxins. They are large, lipid soluble polyethers, and produce symptoms indistinguishable from those of ciguatera. The biological basis of the toxicity is still controversial but there is no doubt that it is neurotoxic. It is probable that many cases of "ciguatera" are misdiagnosed cases of palytoxic poisoning. Properly documented cases are very rare but usually fatal. ${ }^{33}$

\section{General measures to prevent seafood poisoning}

It can be difficult to predict cases of seafood poisoning. The toxic animals exhibit no obvious signs of being poisonous, and of two animals caught in the same area at the same time only one might be poisonous. Therefore care should be taken when eating shellfish, and special caution exercised with very large predatory tropical fish-ideally smaller fish should be consumed. The broth in which the seafood has been cooked should be discarded, and the viscera of any fish should not be consumed. A simple precaution for potentially problematical fish includes rubbing a little raw flesh on the lips before cooking and eating the entire fish-if the lips go numb the fish should be discarded Extensive washing of seafood is not a suitable precaution; for example, boiling mussels for three hours only reduces okadaic acid levels by $50 \%$. It can take days to reduce the toxicity of affected food items by simply soaking in clean water. No seafood should be collected or consumed during or for several days after a bloom (red or green tide). No seafood should ever be eaten uncooked and only freshly caught fish should be purchased.

\section{Differential diagnosis of seafood poisoning}

The differential diagnosis of seafood poisoning is by exclusion. The following factors may be helpful:

l Was the food properly cooked? The consumption of uncooked seafood can be the cause of botulism and meningitis (a result of infestation with Angiostrongylus cantonensis). This form of meningitis has an incubation period of four to six weeks.

2 Was the food fresh when purchased and prepared? Some fish (especially mackerel, tuna, and bonito) convert histidine to histamine if kept at ambient temperature for several hours and this causes scromboid poisoning. The symptoms are caused by the histamine (headache, nausea, urticaria, flushing and fever, gastric pain) and can be treated with antihistamines. Other fish kept for long periods may be dusted with organophosphates or other insecticides to allow flies to be brushed off easily.
3 Were the food items invertebrate (for example, filter feeding shellfish) or vertebrate? Ciguatera is unlikely to be the diagnosis for invertebrate food poisoning. Of the types of shellfish poisonings paralytic shellfish poisoning, with its neurological features of neuromuscular weakness, is the most important.

4 Was the fish consumed a large pelagic fish? If yes, the problem is almost certainly ciguatera. The likelihood of ciguatera is also stronger if the place where the fish was caught was from a reef area anywhere in the Caribbean or Pacific, or off the coast of Florida or Queensland. Palytoxic poisoning will be indistinguishable from ciguatera even if small reef grazers (file fish, parrot fish, surgeon fish) have been consumed as all of these fishes may accumulate either (or both) ciguatoxins and palytoxin.

5 Was the fish a puffer fish? If so a tetrodotoxic poisoning is probable.

As a note of caution, it is becoming increasingly clear that in the tropics animals that either graze on coral reefs or feed in the benthos may accumulate a range of potential toxins, all of which enter the food chain. The hapless human victim may therefore in turn have accumulated a cocktail of toxins.

J Neurol Neurosurg Psychiatry 2002;73:103-109

A Goonetilleke, Department of Neurology, Newcastle General Hospital, Regional Neurosciences Centre, Newcastle upon Tyne NE4 6BE, UK

J B Harris, School of Neurosciences and Psychiatry, The Medical School, University of Newcastle, Newcastle upon Tyne, UK

Correspondence to: $\operatorname{Dr}$ A Goonetilleke; ajith.goonetilleke@ncl.ac.uk

\section{REFERENCES}

1 World Health Organisation. Progress in the characterization of venoms and standardization of antivenoms. WHO Offset Publ No 58. Geneva: WHO, 1981.

2 Stone BF. Tick paralysis, particularly involving Ixodes holocyclus and other Ixodes species. In: Harris KF, ed. Advances in disease vector research. Vol 5. New York: Springer-Verlag, 1988:61-85

3 Pearn J. Neurology of ciguatera. J Neurol Neurosurg Psychiatry $2001 ; 70: 4-8$

4 Miller DM. Ciguatera seafood toxins. Miller DM. Ciguatera seafood toxins
Boca-Raton, FL: CRC Press, 1991.

5 Blain PG, Harris JB. Medical neurotoxicology: occupational and environmental causes of neurological dysfunction. London: Arnold, 1999.

6 Spencer PS, Schaumberg HH. Experimental and clinical neurotoxicology. 2nd edn. Baltimore: Williams and Wilkins, 2000.

7 Boulain J-C, Ménez A. Neurotoxin-specific immunoglobulins accelerate dissociation of the neurotoxin-receptor complex. Science 1982;217:732-3.

8 Reid HA Lim KJ. Sea-snake bite. A survey of fishing villages in north west Malaya. BM 1957; ii:1266-72. 
9 Warrell DA, Looareesuwan S, White NJ, et al. Severe neurotoxic envenoming by the Malayan krait Bungarus candidus (Linnaeus): response to antivenom and anticholinesterase. BM Clin Res Ed 1983;286:678-80.

10 Laothong C, Sitprija V. Decreased parasympathetic activities in Malayan krait (Bungarus candidus) envenoming. Toxicon 2001;39:1353-7.

11 Tun-Pe, Phillips RE, Warrell DA, et al. Acute and chronic pituitary failure resembling Sheehan's syndrome following bites by Russell's viper in Burma. Lancet 1987;ii:763-7.

12 Kouyoumdiian JA, Polizelli C, Lobo SHA, et al. Fatal extradural haematoma after snake bite (bothrops moojeni). Trans Roy Soc Trop Med Hyg 1991;85:552

13 Warrell DA. Tropical snake bite:clinical studies in South East Asia. In: Harris KF, ed. Natural toxins. Oxford: Clarendon Press, 1986:25-45

14 Trestrail JH 3rd. In: Bites and stings of poisonous insects. National Poisons Information, 1983.

15 Karcioglu O, Gumustekin M, Tuncok Y, et al. Acute renal failure following latrodectism. Vet Hum Toxicol 2001;43:161-3.

16 Rosenthal G, Marcus M, Bakalash S, et al. Late Horner's syndrome following the bite of a black widow spider. Int Ophthalmol 2000;23: 1 15-16.
17 Browne GJ. Near fatal envenomation from a funnel-web spider in an infant. Pediatr Emerg Care 1997; 13:271-3.

18 De-Matos IM, Talvani A, Rocha OO, et al. Evidence for a role of mast cells in the lung edema induced by Tityus serrulatus venom in rats. Toxicon 2001;39:863-7.

19 Cooper BJ, Spence I. Temperature-dependent inhibition of evoked acetylcholine release in tick paralysis. Nature 1976;263:693-5.

20 Grattan-Smith PJ, Morris JG, Johnston HM, et al. Clinical and neurophysiological features of tick paralysis. Brain 1997; 120:1975-87.

21 Garrettson LK. Poisoning. In: Pellock JM, Myer EC, eds. Neurological emergencies in infancy and childhood. Philadelphia, PA: Harper and Row, 1984:187.

22 Baden D-Ct. Marine food-borne dinoflagellate toxins. Int Rev Cytol 1983:82:99-150

23 Adachi R, Fukuyo Y. The thecal structure of marine toxic dinoflagellate Gambierdiscus toxicus gen. et sp. Nov. collected in a ciguatera-endemic area. Bulletin of the Japanese Society of Science of Fish 1979:45:67-71.

24 Bagnis R, Chanteau S, Chungue $E$, et al. Origins of ciguatera fish poisoning: a new dinoflagellate, Gambierdiscus toxicus Adachi and Fukuyo, definitely involved as a causal agent. Toxicon 1980;18:199-208.
25 Halstead BW. Fish poisonings - their diagnosis, pharmacology and treatment. Clin Pharmacol Ther 1964;5:615-27

26 Hughes JM, Merson MH. Fish and shellfish poisoning. N Engl J Med 1976;295:111720.

27 Palafox NA, Jain LG, Pinano AZ, et al Successful treatment of ciguatera fish poisoning with intravenous mannitol. JAMA 1988;259:2740-2

28 Pearn JH, Lewis R, Ruff T, et al. Ciguetera and mannitol. Experience with a new treatment regimen. Med J Aust 1989;151:77-80.

29 Bagnis R, Kuberski T, Laugier S. Clinical observations on 3009 cases of ciguatera (fish poisoning) in the South Pacific. Am J Trop Med Hyg 1979;28: 1067-73.

30 McCollum JPK, Pearson RCM, Ingham HR, et al. An epidemic of mussel poisoning in north-east England. Lancet 1968;ii:767-70.

31 Perl TM, Bedard L, Kosatsky T, et al. An outbreak of toxic encephalopathy caused by eating mussels contaminated with domoic acid. N Engl J Med 1990;322:1775-80.

32 Sun K, Wat J, So P. Puffer fish poisoning. Anaesth Intens Care 1994;22:307-8.

33 Alcala AC, Alcala LC, Garth JS, et al. Human fatality due to ingestion of the crab Demania reynaudii that contained a palytoxin-like toxin. Toxicon 1988;26:105-7.

\section{Call for peer reviewers}

Clinical Evidence is a regularly updated evidence based journal available world wide both as a paper version and on the internet. Clinical Evidence urgently needs to recruit a number of new contributors. Contributors are health care professionals or epidemiologists with experience in evidence based medicine and the ability to write in a concise and structured way.

Clinical Evidence needs to recruit a number of new peer reviewers. Peer reviewers are health care professionals or epidemiologists with experience in evidence based medicine. As a peer reviewer you would be asked for your views on the clinical relevance, validity and accessibility of specific topics within the journal, and their usefulness to the intended audience (international generalists and health care professionals, possibly with limited statistical knowledge). Topics are usually 2000-3000 words in length and we would ask you to review between 2-5 topics per year. The peer review process takes place throughout the year, and our turnaround time for each review is ideally 10-14 days.

If you are interested in becoming a peer reviewer for Clinical Evidence, please complete the peer review questionnaire at www.clinicalevidence.com or contact Polly Brown (pbrown@bmigroup.com). 